\title{
Application of information-motivation- behavioral skills model in adherence to diet and reduction of depression among HIV-positive patients: health promotion strategy 90-90-90
}

\author{
Moradali Zareipour ${ }^{1}$, Mohammad Ali Morowatisharifabad², Ehsan Movahed ${ }^{3}$, Mahdieh Hosseinzadeh $^{4}$ \\ Mahboobe Ameri ${ }^{3,5}$ \\ ${ }^{1}$ Health System Research Unit, Health Center of Urmia, Urmia University of Medical sciences, Urmia, Iran \\ ${ }^{2}$ Elderly Health Research Center, School of Public Health, Shahid Sadoughi University of Medical Sciences, Yazd, Iran \\ ${ }^{3}$ Department of Public Health, School of Public Health, Jiroft University of Medical Sciences, Jiroft, Iran \\ ${ }^{4}$ Nutrition and Food Security Research Center, Shahid Sadoughi University of Medical Sciences, Yazd, Iran \\ ${ }^{5}$ School of Public Health, Kerman University of Medical Sciences, Kerman, Iran
}

\begin{abstract}
Introduction: Nutrition, an important component of health, promotes immune system function in patients with human immunodeficiency virus (HIV)/acquired immunodeficiency syndrome (AIDS). Considering that chronic diseases cause depression in these patients, we aimed to investigate the effectiveness of the information-motivation-behavioral skills (IMB) model in adherence to diet and depression among HIV-positive patients.

Material and methods: This intervention was conducted among $122 \mathrm{HIV} /$ AIDS patients over 18 years of age, who referred to the Behavioral Clinic of Kerman Province, Iran in 2018. The census sampling method was applied and 122 patients were selected. Later, the participants were divided into the intervention and control groups randomly. The educational intervention was performed according to the IMB model for the intervention group, while the control group did not receive any training program. Finally, the standard Beck Depression Inventory and the 24-hour recall questionnaire were administered among all participants prior to and 3 months after the intervention. Finally, the data were analyzed by SPSS 24 using descriptive analysis, the Mann-Whitney test, and the paired-sample $t$-test. Results: A total of $122 \mathrm{HIV} / \mathrm{AIDS}$ patients with an average age of $41.88 \pm 9.46$ years participated in the study. After the intervention, the mean energy intake (410.92 \pm 103.37$)$, total fat (24.08 \pm 7.9$)$, saturated fat $(7.39 \pm 0.80)$, and sugar $(35.96 \pm 13.70)$ intake decreased in the intervention group. The difference in depression scores was not significant before and after the intervention $(p=0.2)$ in HIV/AIDS patients who had depression $(72.1 \%)$.

Conclusions: The IMB model can be effective in promoting adherence to a healthy diet, but it failed to reduce depression in HIV patients. Therefore, these patients are recommended to attend group therapy counseling based on cognitive-social theory to reduce depression.
\end{abstract}

HIV AIDS Rev 2021; 20, 3: 187-194 DOI: https://doi.org/10.5114/hivar.2021.109649

Key words: depression, information-motivation-behavioral skills (IMB) model, diet adherence, HIV/AIDS.

Address for correspondence: Ehsan Movahed,

Department of Public Health, School of Public Health, Jiroft University of Medical Sciences, Jiroft, Iran,

e-mail: ehsanmovahed89@yahoo.com
Article history:

Received: 09.08.2020

Received in revised form: 29.09 .2020

Accepted: 30.09.2020

Available online: 30.06 .2021
International Journal of HIV-Related Problem

HIV \& AIDS Re vi e w 


\section{Introduction}

According to the World Health Organization (WHO), acquired immune deficiency syndrome (AIDS) is a major public health problem worldwide [1]. The Joint United Nations Programme on HIV/AIDS (UNAIDS) introduced the 90-90-90 goals in 2013 to help guide efforts to end the HIV epidemic by 2030 [2]. Currently, HIV is considered as a chronic disease and diet adherence is one of the major challenges in patients with chronic diseases [3]. So, nutrition should be considered as a critical component of immune functioning because nutrient deficiency impairs the immune responses. In people living with HIV (PLHIV), this impairment is associated with reduced ability to absorb nutrients and increased metabolic need to fight the disease [4]. This hastens CD4 decline, shortening survival time [5].

Inadequate protein intake hastens muscle mass loss and disease progression. Indeed, malnutrition and HIV have compound and synergistic effects on the immune system [6]. Prior research suggests that nutrition training and/or food supplements can improve health outcomes for HIV-positive individuals over time. Therefore, diet adherence is very important in improving HIV/AIDS patients' health $[7,8]$. Interventions that target food insecurity and diet adherence have the potential to improve treatment adherence and decrease the rates of transmission and mortality. A cohort study on American adult PLHIV with chronic diarrhea reported that the mean intake of fat, saturated fat, and cholesterol was higher than the recommended levels set by the National Cholesterol Education Program. However, the mean intake of monounsaturated fat, polyunsaturated fat, and fiber fell below the recommended levels [9].

Furthermore, the metabolic syndrome (MeS), present in the HIV population, is associated with disorders in lipid and glucose metabolism and central obesity, which may upset the nutritional balance in patients[10]. Filteau et al. reported that vitamins and minerals added to lipid-based nutrient supplements (LNS-VM) increased CD4 count and some anthropometric measures [11]. Another important challenge faced by AIDS patients is depression [12, 13], so that depression is predicted to be one of the three main causes of disease along with AIDS and ischemic heart diseases throughout the world by 2030 [14]. Depression, as a very common disease, has a lifetime prevalence rate of about $15-22 \%$ in the global general population [15]. Among individuals with chronic illnesses such as HIV, the prevalence of depression is 9 to $45 \%[16,17]$. Furthermore, depression can directly impact HIV clinical progression and is associated with higher morbidity and mortality [18]. The prevalence of depression among HIV-positive patients was 50\% in San Francisco. The prevalence of moderate to severe depression among PLHIV was 68\% in Iran [19].

One of the models widely used in adherence is the IMB Model [20]. In this model, information is considered as the prerequisite of personal and social motivation, while risk perception is a motivational prerequisite for learning skills [21]. In the study of Ameri et al. in 2020, the IMB model was found to be effective in diet adherence [22]. Therefore, this study was conducted to answer one main research question: Can the IMB model be effective in diet adherence and depression?

\section{Material and methods}

\section{Study design and setting}

This interventional study was carried out on HIV/AIDS patients with 18 years of age and over, who referred to the Behavioral Disease Counseling Center in Kerman City, Iran in 2018.

\section{Participants and sampling}

The available sampling method was used and 183 eligible individuals with active records were selected. A total of 122 people participated in the study. In order to select the participants, questionnaires were distributed among the patients who referred to the Behavioral Disease Counseling Center for receiving counseling. These people were categorized into the intervention and control groups randomly. The intervention group members attended the educational sessions conducted based on the IMB model, while the control group members received the routine services. After three months, the same questionnaire was administered as the follow-up. To determine the sample size, pre- and post-intervention adherence ratios of $5 \%$ and $75 \%$, respectively, reported in similar studies [23], were considered. Furthermore, $80 \%$ test power, 5\% type I error, and coverage of all study objectives were considered and the sample size was calculated as 61 individuals per group. So, the research was conducted on the other participants after obtaining informed consent forms. Inclusion criteria were being 18 years old or over, consuming antiviral medications for 6 months, and being willing to participate in the study.

\section{Intervention}

The intervention consisted of at least 8 training sessions (90 minutes per session according to the participants) over a 12-week period on behavioral adherence to nutrition activity based on the IMB model for the intervention group. However, the control group did not receive any educational intervention. Every two weeks, phone calls were made to remind participants about adherence to the educational contents.

The first and second sessions were conducted using collaborative teaching method by patient friends, questionand-answer method, lecture-guided method, and using Medical Nutrition Therapy for HIV and AIDS guidelines.

In the educational sessions, the patients were provided with some information about fat lipodystrophy syndrome, the food pyramid, food diversity and balance, daily energy intake, as well as the benefits of fruits, vegetables, and fish. 
These two sessions were implemented within one week to raise the participants' awareness. The third and fourth sessions were held to increase the participants' motivation for 3 weeks. The motivational construct consisted of three parts: personal motivation, social motivation, and perceived sensitivity (perceived risk). In personal motivation, encouragement, determination of appropriate goals, SMS technology, and accuracy in sending messages at the right time (message timing control) were applied. In addition, a motivational interview was conducted based on empathy and open discussion using open-ended questions. Through the interviews, the researcher tried to avoid contention, showed approval of desirable behaviors, and used brainstorming, such as discussing about social stigma and fitness, nutrition and depression, social acceptance, and proper nutrition. Finally, the value of the consequences of good behaviors was discussed.

In social motivation, participants were asked to mention the name of a supportive partner or good friend, who could solve their adherence problem. Given the low level of literacy of the target group in the risk perception construct, the scenario method was used by presenting statistics. The fifth, sixth, and seventh sessions were used to increase the behavioral skills over a period of 3 weeks including self-efficacy and objective behavioral skills. Regarding the self-efficacy section, the practical demonstration, group discussion (6 to 8 people), and group problem solving methods were used. In the objective skill section, healthier role models and ability to tackle barriers to correct behavior were covered through MMS video message technology and development of stretch-and-flexibility training videos for HIV patients. Furthermore, we tried to use the self-monitoring method, in which each patient in the intervention group was provided with a daily calendar and asked to list the events leading to adherence and non-adherence. Later, the participants discussed these factors and events with each other in the training sessions. The eighth session was conducted one month after the seventh session to follow up the participants, review the covered issues, and solve patients' possible problems in the adherence process.

\section{Measures}

In this research, three questionnaires were applied to collect the data. The first questionnaire collected the demographic and clinical data of the patients including age, sex, marital status, educational level, occupation, income level, number of children, housing, disease transmission forms, CD4 count, stage of disease, viral load, risk factors, history of disease, body mass index, weight, height, mid-arm circumference, waist circumference, as well as hip and muscle circumference.

\section{The second questionnaire was the food recall questionnaire}

In this questionnaire, participants were required to report the amount of food taken at each meal during the past
24 hours on three non-consecutive days, including a holiday. The questionnaire consisted of three parts including the name of the meal, the name of the food, and the amount of each food. This questionnaire was used by Movahed [24] on HIV-positive patients After the patients registered their information in the food recall questionnaire, the portions were converted into grams and registered in the N4 program. After the food data were recorded, the outputs were entered into Excel and the extracted data were transferred to SPSS version 22 .

\section{Beck Depression Inventory II test}

The Beck Depression Inventory-II (BDI-II) is widely used to diagnose depression and measure its severity. Kanmogne et al. investigated the validity and reliability of the French version of this questionnaire in Cameroon [25]. The BDI-II consists of 21 items to evaluate the emotional factors of depression, such as hopelessness, irritability, guilty feelings, pessimism, worthlessness, self-efficacy, and suicidal thoughts, as well as physical factors such as loss of appetite, fatigue, as well as sleep and concentration problems. The options were scored from zero to three and the total score was calculated to determine the severity of depression: normal (0-13), mild (14-19), moderate (20-28), and severe (29-63).

\section{Data collection and ethical considerations}

After obtaining the code of ethics from the Ethics Committee of Yazd University of Medical Sciences (IR.SSU.SPH.REC 1396.83), it was also approved in the Iranian Registry of Clinical Trials with number IRCT20181112041616 N1. Researchers obtained the list of eligible individuals by referring to the Behavioral Diseases Counseling Center, Kerman, Iran. Prior to sampling, participants were provided with explanations about the study purpose and informed consent forms were obtained from them. Furthermore, they were ensured about confidentially of information. In order to achieve the patients' higher satisfaction, female and male colleagues were asked to complete the questionnaires for female and male patients, respectively. Due to the high stigma of the disease, those who did not wish to complete the questionnaires at the Counseling Center were allowed to complete the questionnaire at home and deliver the complete questionnaire to the center head or researcher after one week. In order to obtain more precise answers in completing the questionnaires, each participant was paid $\$ 3$. Finally, all questionnaires were returned.

\section{Statistical analysis}

Descriptive statistics (frequency, percentage, mean, and standard deviation) were used to describe the study 
Table 1. Demographics and clinical information of the study samples $(N=122)$

\begin{tabular}{|c|c|c|}
\hline Variable & $n$ & $\%$ \\
\hline \multicolumn{3}{|l|}{ Sex } \\
\hline Female & 57 & 46.7 \\
\hline Male & 65 & 53.3 \\
\hline \multicolumn{3}{|l|}{ Marital status } \\
\hline Single & 29 & 22.8 \\
\hline Married & 57 & 46.7 \\
\hline Divorced/Widow & 26 & 29.5 \\
\hline \multicolumn{3}{|l|}{ Education } \\
\hline Illiterate & 13 & 10.7 \\
\hline Elementary & 32 & 26.2 \\
\hline Middle school & 32 & 26.2 \\
\hline Diploma and higher & 45 & 36.9 \\
\hline \multicolumn{3}{|l|}{ Job } \\
\hline Unemployed & 66 & 54.1 \\
\hline Employed & 56 & 45.9 \\
\hline \multicolumn{3}{|l|}{ Children } \\
\hline 0 & 41 & 33.6 \\
\hline 1 & 31 & 25.4 \\
\hline 2 and more & 50 & 41.0 \\
\hline \multicolumn{3}{|l|}{ Housing } \\
\hline Owned & 48 & 39.3 \\
\hline Rented & 54 & 44.3 \\
\hline Others & 20 & 16.4 \\
\hline \multicolumn{3}{|l|}{ Income } \\
\hline$<$ US \$60 & 71 & 58.2 \\
\hline$>$ US $\$ 60$ & 51 & 41.8 \\
\hline \multicolumn{3}{|l|}{ Disease transmission form } \\
\hline Sexual intercourse & 46 & 37.7 \\
\hline Injection & 29 & 23.8 \\
\hline I do not know & 27 & 22.1 \\
\hline Others & 20 & 16.4 \\
\hline \multicolumn{3}{|l|}{ BMI } \\
\hline Normal (18.5-24.9) & 57 & 46.7 \\
\hline Less than normal $(<18.5)$ & 13 & 10.7 \\
\hline More than normal (> 24.9) & 52 & 42.6 \\
\hline \multicolumn{3}{|l|}{ CD4 count } \\
\hline$\leq 100$ & 11 & 9 \\
\hline $101-200$ & 16 & 13.1 \\
\hline $201-350$ & 23 & 18.9 \\
\hline$\geq 350$ & 72 & 59 \\
\hline \multicolumn{3}{|l|}{ Disease stage } \\
\hline HIV & 114 & 93.4 \\
\hline AIDS & 8 & 6.6 \\
\hline
\end{tabular}

Table 1. Cont.

\begin{tabular}{|c|c|c|}
\hline Variable & $n$ & $\%$ \\
\hline \multicolumn{3}{|l|}{ Viral load } \\
\hline$<100$ & 78 & 63.9 \\
\hline$\geq 100 r$ & 44 & 36.1 \\
\hline \multicolumn{3}{|l|}{ Risk factors } \\
\hline No & 51 & 41.8 \\
\hline Yes $^{*}$ & 71 & 58.2 \\
\hline \multicolumn{3}{|l|}{ Disease history } \\
\hline Less than 5 years & 37 & 30.3 \\
\hline $5-10$ & 37 & 30.3 \\
\hline $10-15$ & 20 & 16.4 \\
\hline$\geq 15$ & 28 & 23 \\
\hline
\end{tabular}

* Cigarette, drug abuse, methadone, alcohol, others

population with regard to general characteristics and diet adherence. The paired $t$-test was run to compare the mean and standard deviation of adherence to diet according to the parametric conditions. Finally, SPSS version 25 was used for data analysis.

\section{Results}

A total of 122 HIV/AIDS patients with a mean age of $41.88 \pm 9.46$ years participated in the study. Of all participants, $53.3 \%$ were male, $46.7 \%$ were married, $36.9 \%$ had a diploma or higher education levels, $54.1 \%$ were unemployed, $33.6 \%$ had no children, and the rest had at least one child. Furthermore, $41.8 \%$ of the participants had an income of more than $\$ 48$. According to Table 1, the disease was transmitted by sex in $37.7 \%$ of individuals, BMI was normal in $46.7 \%$ of patients, and the CD4 level was higher than 350 in $59 \%$ of participants. According to the findings, $93.4 \%$ of the participants had HIV, the viral load was less than 100 in $63.9 \%$ of patients, and $41.8 \%$ of them did not mention risk factors such as substance use. The BMI was also calculated as $23.5 \pm 5.49$.

According to Table 2, the average kilocalories, total fat, saturated fat, and sugar decreased after the intervention. Moreover, the mean values of protein $(p=0.04)$, fiber $(p=0.006)$, and vitamin $(p=0.03)$ were significantly different between the intervention and control groups.

Based on the findings, $27.9 \%$ of the participants had no depression. Among patients who had depression (72.1\%), $29 \%$ had severe depression and the others had moderate to low levels of depression (Table 3).

The depression prevalence did not differ before and after the intervention based on the IMB model in HIV/AIDS patients $(p=0.2)$ (Table 4$)$. 
Application of information-motivation-behavioral skills model in adherence to diet and reduction of depression among HIV-positive patients: health promotion strategy $90-90-90$

Table 2. Mean and standard deviation of food intake in HIV-positive patients before and after intervention

\begin{tabular}{|c|c|c|c|}
\hline \multirow[t]{2}{*}{ Variable/Stage } & Intervention group & Control group & \multirow[t]{2}{*}{$p$-value } \\
\hline & Mean (SD) & Mean (SD) & \\
\hline \multicolumn{4}{|c|}{ Cholesterol (mg) per day } \\
\hline Pre-intervention & $214.28 \pm 32.34$ & $171.41 \pm 31.63$ & 0.31 \\
\hline Post-intervention & $173.23 \pm 28.92$ & $188.88 \pm 27.42$ & 0.69 \\
\hline$p$-value & 0.11 & 0.33 & \\
\hline Mean differences & $41.05 \pm 31.68-$ & $17.47 \pm 26.10+$ & 0.3 \\
\hline \multicolumn{4}{|l|}{ Protein (g) } \\
\hline Pre-intervention & $52.38 \pm 3.68$ & $46.79 \pm 3.45$ & 0.2 \\
\hline Post-intervention & $44.40 \pm 2.87$ & $36.67 \pm 2.59$ & 0.04 \\
\hline$p$-value & 0.05 & 0.02 & \\
\hline Mean differences & $7.97 \pm 31.09-$ & $-10.12 \pm 33.47$ & 0.7 \\
\hline \multicolumn{4}{|l|}{ Calories per day } \\
\hline Pre-intervention & $1693.49 \pm 145.22$ & $1363.80 \pm 92.45$ & 0.058 \\
\hline Post-intervention & $1282.57 \pm 78.84$ & $1029.20 \pm 68.61$ & 0.01 \\
\hline$p$-value & 0.003 & 0.006 & \\
\hline Mean differences & $410.92 \pm 103.37-$ & $334.60 \pm 95.25$ & 0.8 \\
\hline \multicolumn{4}{|l|}{ Total fat (g) } \\
\hline Pre-intervention & $70.86 \pm 9.20$ & $45.47 \pm 5.68$ & 0.02 \\
\hline Post-intervention & $46.78 \pm 6.78$ & $36.57 \pm 3.67$ & 0.18 \\
\hline$p$-value & 0.01 & 0.19 & \\
\hline Mean differences & $-24.08 \pm 7.9$ & $-8.89 \pm 5.56$ & 0.2 \\
\hline \multicolumn{4}{|l|}{ Sugar (g per day) } \\
\hline Pre-intervention & $79.53 \pm 17.36$ & $51.84 \pm 7.74$ & 0.12 \\
\hline Post-intervention & $43.56 \pm 5.20$ & $36.67 \pm 5.31$ & 0.35 \\
\hline$p$-value & 0.04 & 1.21 & \\
\hline Mean differences & $-35.96 \pm 13.70$ & $-15.16 \pm 7.26$ & 0.7 \\
\hline \multicolumn{4}{|l|}{ Saturated fat } \\
\hline Pre-intervention & $19.64 \pm 2.98$ & $10.06 \pm 0.94$ & 0.003 \\
\hline Post-intervention & $12.25 \pm 2.18$ & $9.1 \pm 0.81$ & 0.18 \\
\hline$p$-value & 0.03 & 0.6 & \\
\hline Mean differences & $7.39 \pm 0.80$ & $-0.96 \pm 0.13$ & 0.1 \\
\hline \multicolumn{4}{|l|}{ Fiber (g) daily } \\
\hline Pre-intervention & $3.82 \pm 0.33$ & $3.56 \pm 0.22$ & 0.51 \\
\hline Post-intervention & $3.80 \pm 0.27$ & $2.81 \pm 0.23$ & 0.006 \\
\hline$p$-value & 0.97 & 0.01 & \\
\hline Mean differences & $-0.01 \pm 0.7$ & $-0.7 \pm 0.37$ & 0.1 \\
\hline \multicolumn{4}{|l|}{ Vitamin (mg per day) } \\
\hline Pre-intervention & $58.75 \pm 6.88$ & $64.53 \pm 8.71$ & 0.63 \\
\hline Post-intervention & $57.35 \pm 9.38$ & $32.20 \pm 6.55$ & 0.03 \\
\hline$p$-value & 0.89 & 0.002 & \\
\hline Mean differences & $-1.40 \pm 8.36$ & $-32.33 \pm 7.43$ & 0.03 \\
\hline
\end{tabular}


Table 3. Severity of depression in people living with HIV

\begin{tabular}{l|c|c}
\hline Variable/Severity & $n$ & $\%$ \\
\hline \multicolumn{3}{l|}{ Depression } \\
\hline Mild & 23 & 27 \\
\hline Moderate & 19 & 15.6 \\
\hline Severe & 36 & 29.5 \\
\hline Normal (no) & 34 & 27.9 \\
\hline Total & 122 & 100 \\
\hline
\end{tabular}

Table 4. Differences of depression prevalence before and after the intervention based on the IMB model

\begin{tabular}{l|c|c|c|c}
\hline & $N$ & $\begin{array}{c}\text { Mean } \\
\text { rank }\end{array}$ & $\begin{array}{c}\text { Sum } \\
\text { of ranks }\end{array}$ & $\begin{array}{c}\text { Difference } \\
\text { before and after } \\
\text { theintervention }\end{array}$ \\
\hline Negative ranks & $60^{\mathrm{a}}$ & 54.47 & 3268.00 & \\
\hline Positive ranks & $47^{\mathrm{b}}$ & 53.40 & 2510.00 & \\
\hline Ties & $15^{\mathrm{c}}$ & & & \\
\hline Total & 122 & & & \\
\hline$Z$ & \multicolumn{5}{|c}{$-1.179^{\mathrm{d}}$} \\
\hline Sig. (2-tailed) & \multicolumn{5}{|c}{0.2} \\
\hline
\end{tabular}

atagdepression_after < tagdepressio_befor

${ }^{b}$ tagdepression_after $>$ tagdepressio_befor

ctagdepression_after $=$ tagdepressio_befor

${ }^{d}$ Based on positive ranks.

\section{Discussion}

The findings showed that the IMB model was suitable and practical for following a healthy treatment diet among PLHIV to achieve the goals of 90-90-90. However, the IMB model could not reduce the prevalence of depression in patients.

Similarly to our study, a recent investigation showed that the mean scores of total fat and saturated fat decreased after intervention in the intervention group. Other studies also indicated that fat and overweight decreased after training intervention in patients who adopted the Mediterranean diet [26, 27]. In contrast, Chien et al. [28] reported no statistically significant difference between the intervention and control groups in terms of adherence to the lowfat diet. The main reason for the statistical discrepancy between outcomes of the two study groups can be attributed to the fact that only one educational session was held and the patients received no follow-up with regard to the educational programs after discharge. As the participants mentioned, one training session may increase the level of awareness about diet among patients and their families, but it is not enough to change the patients' behavior in order to enhance their adherence to diet. According to the results, the significant difference between the two study groups can be attributed to lack of implementing several training sessions, patients' follow-up, and presentation of educational booklets.

In our study, sugar consumption was reduced in the intervention group. In the same vein, Nyamathi et al. [29] found that the intervention group followed a healthy diet after the intervention and decreased consumption of unhealthy foods. In the present study, an educational training method was administered and the participants were provided with information about healthy food. This entailed not only educational training, but also food preparation and healthy cooking methods to follow a healthy diet. Protein and nutrient deficiencies exacerbate immune impairments in HIV-positive individuals in a reciprocal relationship [6]. Our results also showed no differences between the two groups in terms of protein intake. In contrast, Nyamathi et al. [29] conducted an educational intervention based on accredited social health activist (ASHA) behavioral support and found that the amount of received protein increased in the intervention group. In our intervention, HIV patients could not afford to purchase foods due to high sanctions and high prices of protein products. Therefore, one may conclude that educational intervention without providing food is not effective in increasing protein intake.

In the present study, the amount of calories, vitamins, and fiber was reduced after intervention. Sanctions against Iran have put economic pressure on the people, especially HIV patients, and have weakened the effectiveness of the IMB model, but in Ameri et al. the IMB model was effective in adherence to the diet [22]. Similarly to our study, Nyamathi in India reported that food intake was challenging in HIV/AIDS patients, so that lack of resources, stigma, discrimination, and poor behavior of food industry employees reduced food intake in patients [29].

Furthermore, the average intake of fiber, vitamins, and protein was significantly different between the two study groups in our research. In contrast, Aasheim et al. [30] found no statistically significant difference between the group that underwent surgery and the group that underwent lifestyle intervention in terms of vitamins $\mathrm{C}, \mathrm{D}$, and $\mathrm{B}_{1}$. As these researchers showed, only the differences in levels of vitamins $B_{6}$ and $E$ were significant in the group who underwent surgery. So, the results showed that intervention based on the IMB model was more effective than the lifestyle intervention and significant differences were observed between the two groups.

In confirmation of our findings, Barbosa et al. [31] noted that nutritional intervention significantly increased the amount of vitamins and proteins in HIV patients and improved their immune function. Clark [32] and Neves [33] conducted educational, responsive, and skillful interventions during nine weeks to improve the nutritional status of adults. In line with the present study, they found that consumption of fruit and fiber increased after the intervention $(p<0.001)$. In our study, a significant difference was found between the two groups regarding fiber and vitamin levels after the intervention, but the changes were more significant in Clark's study [32]. Such a discrepancy in the findings may be due 
to the variety in participants' demographic and background characteristics. Therefore, long-term model-based interventions are required in HIV/AIDS patients due to the poor financial situation and reduced absorption of substances.

Similarly to our findings, the prevalence of moderate to severe depression in the study by Christopher [34] was higher than the average level, which can be justified by loss of interest, poor motivation, and high stigma in patients. However, Nobakht et al. [35], and Krupa et al. [36] reported the opposite results. A systematic review by Bernard [16] showed a high prevalence of severe depression (13-24\%). Considering that Krupa et al. [36] investigated elderly people over 45 years of age, the discrepancy in the findings can be attributed to the differences in participants' age, environment, and culture.

In our study, depression did not decrease after the intervention, while a 6-week intervention in Tanzania based on group therapy counseling was effective in addressing depression problems in women with HIV [37]. In Uganda, an intervention based on socio-cognitive theories improved the patients' performance and decreased their depression [38]. Consequently, socio-cognitive theories and group counseling are more effective in reducing depression. Some of the major limitations of this study are as follows. 1) Since data were collected in winter, different results may be obtained in other months and seasons. 2) The study duration was short. 3) Administration of self-reporting tools may result in biased findings. 4) Patients did not cooperate properly.

\section{Conclusions}

The IMB model can increase use of healthy foods and is a suitable model in achieving the goals of 90-90-90. However, this model failed to reduce depression in HIV patients despite having a social motivation construct. Therefore, other behavioral counseling centers are recommended to follow IMB models in dietary adherence. Group therapy counseling based on cognitive-social theory is a more appropriate approach in reducing depression.

\section{Acknowledgements}

This study was a research project approved by Yazd University of Medical Sciences, Yazd, Iran (96-04-31-93990). The authors sincerely appreciate all patients who participated in the study. We also thank the director and nurses of Behavioral Disease Counseling Center in Kerman city, Iran.

\section{Conflict of interest}

The authors have no conflict of interest.

\section{References}

1. Morowatisharifabad MA, Movahed E, Farokhzadian J, et al. Antiretroviral therapy adherence based on information, motivation, and behavioral skills model and its association with depression among HIV-positive patients: Health promotion strategy towards the 909090 target. J Educ Health Promot 2019; 8: 192.

2. Parcesepe AM, Mugglin C, Nalugoda F, et al. Screening and management of mental health and substance use disorders in HIV treatment settings in low-and middle-income countries within the global Ie DEA consortium. J Int AIDS Soc 2018; 21: e25101.

3. Alfahad TB, Nath A. Update on HIV-associated neurocognitive disorders. Curr Neurol Neurosci Rep 2013; 13: 387.

4. Zareipour M, Movahed E, Sadeghi R, Sotoudeh A, Sadeghi S, Ameri M. Evaluation of anthropometric indices, eating habits, and their relationship with CD4 level in individuals with HIV/AIDS. HIV AIDS Rev 2020; 19: 237-243.

5. Weiser SD, Young SL, Cohen CR, et al. Conceptual framework for understanding the bidirectional links between food insecurity and HIV/AIDS. Am J Clin Nutr 2011; 94: 1729S-1739S.

6. Anabwani G, Navario P. Nutrition and HIV/AIDS in sub-Saharan Africa: an overview. Nutrition 2005; 21: 96-99.

7. Claros JM, de Pee S, Bloem MW. Adherence to HIV and TB care and treatment, the role of food security and nutrition. AIDS Behav 2014; 18: 459-464.

8. de Pee S, Grede N, Mehra D, Bloem MW. The enabling effect of food assistance in improving adherence and/or treatment completion for antiretroviral therapy and tuberculosis treatment: a literature review. AIDS Behav 2014; 18: 531-541.

9. Capili B, Anastasi JK. Body mass index and nutritional intake in patients with HIV and chronic diarrhea: a secondary analysis. J Am Acad Nurse Pract 2008; 20: 463-470.

10. Ferreira RdS, Guimarães RdCA, Pontes ERJC, Mendonça LABM, Freitas KdC, Hiane PA. Effectiveness of a bioactive food compound in anthropometric measures of individuals with HIV/AIDS: a nonrandomized trial. PLoS One 2018, 13: e0191259.

11. Filteau S, PrayGod G, Kasonka L, et al. Effects on mortality of a nutritional intervention for malnourished HIV-infected adults referred for antiretroviral therapy: a randomised controlled trial. BMC Med 2015; 13: 17.

12. Heaton R, Clifford D, Franklin D, et al. HIV-associated neurocognitive disorders persist in the era of potent antiretroviral therapy: CHARTER Study. Neurology 2010; 75: 2087-2096.

13. Morowatisharifabad MA, Movahed E, Farokhzadian J, et al. Antiretroviral therapy adherence and its determinant factors among people living with HIV/AIDS: a case study in Iran. BMC Res Notes 2019; 12: 162 .

14. Ferrari AJ, Charlson FJ, Norman RE, et al. Burden of depressive disorders by country, sex, age, and year: findings from the global burden of disease study 2010. PLoS Med 2013; 10: e1001547.

15. Kidia K, Machando D, Bere T, et al. 'I was thinking too much': experiences of HIV-positive adults with common mental disorders and poor adherence to antiretroviral therapy in Zimbabwe. Trop Med Int Health 2015, 20: 903-913.

16. Bernard C, Dabis F, de Rekeneire N. Prevalence and factors associated with depression in people living with HIV in sub-Saharan Africa: a systematic review and meta-analysis. PLoS One 2017; 12: e0181960.

17. Gonzalez JS, Batchelder AW, Psaros C, Safren SA. Depression and HIV/AIDS treatment nonadherence: a review and meta-analysis. J Acquir Immune Defic Syndr 2011: 58: 181-187.

18. Leserman J. Role of depression, stress, and trauma in HIV disease progression. Psychosom Med 2008; 70: 539-545.

19. Lari MA, Parsa N, Marzban M, Shams M, Faramarzi H. Depression, testosterone concentration, sexual dysfunction and methadone use among men with hypogonadism and HIV infection. AIDS Behav 2012; 16: 2236-2243.

20. Alexander DS, Hogan SL, Jordan JM, DeVellis RF, Carpenter DM. Examining whether the information-motivation-behavioral skills model predicts medication adherence for patients with a rare disease. Patient Prefer Adherence 2017; 11: 75-83. 
21. Fisher JD, Fisher WA, Shuper PA. The information-motivationbehavioral skills model of HIV preventive behavior. Emerging Theories in Health Promotion Practice and Research 2009; 2: 21-64.

22. Ameri M, Movahed E, Farokhzadian J. Effect of information, motivation, and behavioral skills model on adherence to medication, diet, and physical activity in HIV/ADIS patients: a health promotion strategy. J Educ Health Promot 2020; 9: 317.

23. Kaihin R, Kasatpibal N, Chitreechuer J, Grimes RM. Effect of an empowerment intervention on antiretroviral drug adherence in Thai Youth. Behav Med 2015; 41: 186-194.

24. Ehsan M. Planning, implementation and evaluation. The effect of empowerment program the information-motivation-behaviour skills model-based on adherence to treatment regimen HIV positive patients in Kerman. Yazd: Yazd University of Medical Science; 2018.

25. Kanmogne GD, Qiu F, Ntone FE, et al. Depressive symptoms in HIVinfected and seronegative control subjects in Cameroon: effect of age, education and gender. PLoS One 2017; 12: e0171956.

26. Martínez-González MA, García-Arellano A, Toledo E, et al. A 14item Mediterranean diet assessment tool and obesity indexes among high-risk subjects: the PREDIMED trial. PLoS One 2012; 7: e43134.

27. Nordmann AJ, Suter-Zimmermann K, Bucher HC, et al. Metaanalysis comparing Mediterranean to low-fat diets for modification of cardiovascular risk factors. Am J Med 2011; 124: 841-851.e842.

28. Chien WT, Chiu Y, Lam LW, Ip WY. Effects of a needs-based education programme for family carers with a relative in an intensive care unit: a quasi-experimental study. Int J Nurs Studies 2006; 43: 39-50.

29. Nyamathi AM, Carpenter CL, Ekstrand ML, et al. Randomized controlled trial of a community-based intervention on HIV and nutritional outcomes at six months among women living with HIV/AIDS in rural India. AIDS 2018; 32: 2727.

30. Aasheim ET, Johnson LK, Hofsø D, Bøhmer T, Hjelmesæth J. Vitamin status after gastric bypass and lifestyle intervention: a comparative prospective study. Surg Obes Relat Dis 2012; 8: 169-175.

31. Barbosa MAG, Almeida AMR, Figueiredo MA, et al. Feeding and diabetes mellitus: perception and food consumption by elderly people in the hinterlands of Pernambuco. Brazilian Journal in Health Promotion 2015; 28: 370-378.

32. Clark RL, Famodu OA, Holásková I, et al. Educational intervention improves fruit and vegetable intake in young adults with metabolic syndrome components. Nutr Res 2019; 62: 89-100.

33. Neves FJ, Tomita LY, Liu ASLW, Andreoni S, Ramos LR. Educational interventions on nutrition among older adults: a systematic review and meta-analysis of randomized clinical trials. Maturitas 2020; 136: 13-21.

34. Coleman CL. Health related quality of life and depressive symptoms among seropositive African Americans. Appl Nurs Res 2017; 33: 138-141.

35. Nobakht A, Mohraz M, Rahimzadeh M, Tehranizadeh M, Behboodi-Moghadam Z, Esmaelzadeh-Saeieh S. The effect of cognitive behavioural therapy on depression, anxiety, and stress in women with HIV. HIV AIDS Rev 2018; 17: 218-223.

36. Shah KN, Majeed Z, Yoruk YB, et al. Enhancing physical function in HIV-infected older adults: a randomized controlled clinical trial. Health Psychol 2016; 35: 563.

37. Kaaya SF, Blander J, Antelman G, et al. Randomized controlled trial evaluating the effect of an interactive group counseling intervention for HIV-positive women on prenatal depression and disclosure of HIV status. AIDS Care 2013; 25: 854-862.

38. Nakimuli-Mpungu E, Wamala K, Okello J, et al. Group support psychotherapy for depression treatment in people with HIV/AIDS in northern Uganda: a single-centre randomised controlled trial. Lancet HIV 2015; 2: e190-e199. 